\title{
The relentless march of mass coral bleaching: a global perspective of changing heat stress
}

\author{
W. J. Skirving ${ }^{1,2}$. S. F. Heron ${ }^{1,2,3}$ • B. L. Marsh ${ }^{1,2} \cdot$ G. Liu $^{1,4}$ J. L. De La Cour ${ }^{1,4}$ • \\ E. F. Geiger ${ }^{1,4}$ C. M. Eakin ${ }^{1}$
}

Received: 2 October 2018/Accepted: 1 April 2019/Published online: 17 April 2019

(C) The Author(s) 2019

\begin{abstract}
The global coral bleaching event of 2014-2017 resulted from the latest in a series of heat stress events that have increased in intensity. We assessed global- and basinscale variations in sea surface temperature-based heat stress products for 1985-2017 to provide the context for how heat stress during 2014-2017 compared with the past 3 decades. Previously, undefined "Heat Stress Year" periods (used to describe interannual variation in heat stress) were identified for the Northern and Southern Hemispheres, in which heat stress peaks during or shortly after the boreal and austral summers, respectively. The proportion of reef pixels experiencing bleaching-level heat stress increased through the record, accelerating during the last decade. This increase in accumulated heat stress at a bleaching level is a result of longer stress events rather than an increase in the peak stress intensity. Thresholds of heat stress extent for the three tropical ocean basins were established to designate "global" events, and a Global Bleaching Index was defined that relates heat stress extent
\end{abstract}

Topic Editor Morgan S. Pratchett

W. J. Skirving

william.skirving@noaa.gov

1 NOAA/NESDIS/STAR Coral Reef Watch, 5830 University Research Court, College Park, MD 20740, USA

2 ReefSense, P.O. Box 343, Aitkenvale BC, Aitkenvale, QLD 4814, Australia

3 Marine Geophysical Laboratory, Physics Department, College of Science and Engineering, James Cook University, Townsville, QLD 4811, Australia

4 Earth System Science Interdisciplinary Center/Cooperative Institute for Climate and Satellites-Maryland, University of Maryland, STAR/NESDIS/NOAA Affiliate, 5825 University Research Court, College Park, MD 20740, USA to that observed in 1998. Notably, during the 2014-2017 global bleaching event, more than three times as many reefs were exposed to bleaching-level heat stress as in the 1998 global bleaching.

Keywords Coral bleaching - Heat stress - Coral Reef Watch · DHW · Hotspot - CoralTemp

\section{Introduction}

The global coral bleaching event spanning 2014-2017 was the longest, most extensive, most intense (in terms of accumulated heat stress) and probably most damaging (in terms of coral mortality) ever recorded (Eakin et al. 2017). The event coincided with three consecutive record-setting years for globally averaged surface temperature: 2014 set a record that was surpassed in 2015, which in turn was surpassed in 2016; global temperature during 2017 was the third highest on record (Blunden and Arndt 2018). Anomalously, warm ocean temperatures from 2014 to 2017 were associated with the El Niño-Southern Oscillation (ENSO; Blunden and Arndt 2018), and oceanographic phenomena, such as "the blob" (Bond et al. 2015). Mass coral bleaching has been long associated with temperature above expected summertime conditions (Glynn and D'Croz 1990; Jokiel and Coles 1990; Hoegh-Guldberg 1999). Many coral reef areas experienced their worst observed bleaching and more than half bleached twice or more during the 36-month period, 2014-2017 (Eakin et al. 2017). A more complete understanding of this global event can be achieved by considering the context of global and regional heat stress through time.

Here, we examine two coral-specific products from the National Oceanic and Atmospheric Administration 
(NOAA) Coral Reef Watch (CRW) heat stress product suite: HotSpot (HS), a measure of daily coral heat stress, and Degree Heating Week (DHW), a measure of accumulated coral heat stress. HS is a positive anomaly product based on the difference between the daily sea surface temperature (SST) and the maximum monthly mean (MMM) climatology, whereas DHW is an accumulation of HS values (Liu et al. 2013, 2014, 2017). Using these products, we assess global- and basin-scale variations for 1985-2017 and place the global coral bleaching event of 2014-2017 into the context of heat stress over the past 3 decades.

\section{Materials and methods}

\section{Datasets}

Developed by the NOAA CRW program, the recently released CoralTemp Version 1.0 SST data product provides, for the first time, a single dataset at a resolution comparable with the scale of many coral reefs $(\sim 5 \mathrm{~km})$ that is spatially and temporally replete. CoralTemp uses three separate but related level-4 (using multiple sensors, spatially and temporally replete; Merchant et al. 2014) satellite SST products that have consistent bias correction through time to provide a continuous record of daily, global SST data at 0.05 degree resolution, spanning the period January 1, 1985 to the present (https://coralreef watch.noaa.gov/product $/ 5 \mathrm{~km} /$ index_5km_sst.php). The products are (i) the United Kingdom Met Office Operational SST and Sea Ice Analysis, reasnalysis (OSTIA; Roberts-Jones et al. 2012), which is used to cover 1985-2002; and (ii) the NOAA/National Environmental Satellite, Data, and Information Service's (NESDIS) Geostationary-Polar-orbiting Blended Night-only SST Analysis reanalysis (2002-2016) and (iii) operational near real-time (2017-present) products (Maturi et al. 2017). The combination of $5 \mathrm{~km}$ resolution and consistency through time (historical to near real-time) in the CoralTemp dataset is unique among global SST datasets, thus providing an unprecedented opportunity to directly compare historical conditions with near real-time observations at reef scale for coral reef locations.

Based on the initial release of CoralTemp, CRW has updated its heat stress product suite (to Version 3.1), providing a dataset of anomaly-based products that are well suited to the investigation of coral heat stress over the past 3 decades. Two of these CRW products (HS and DHW) were analysed to describe global heat stress for the period 1985-2017. Heat stress is present for a coral location when HS (https://coralreefwatch.noaa.gov/product $/ 5 \mathrm{~km} /$ index_ $5 \mathrm{~km} \_$hs.php) reaches or exceeds $1{ }^{\circ} \mathrm{C}$. Accumulated heat stress, as measured by DHW (https://coralreefwatch.noaa. gov/product/5km/index_5km_dhw.php), provides the best predictor of bleaching onset and severity (e.g. Eakin et al. 2010; Heron et al. 2016a). Details of the derivation of these metrics can be found in Liu et al. (2014); Version 3.1 of these products uses the SST climatology calculated from the initial release of CoralTemp, as described in Liu et al. (2017).

Analyses were undertaken using only values at coral reef locations compiled at $5 \mathrm{~km}$ resolution by CRW from multiple data sources (described in Heron et al. 2016a). Northern and Southern Hemispheres were analysed separately, as were the northern and southern portions of each ocean basin (Indian, Pacific and Atlantic). Numbers of reef-containing pixels for each region are listed in Table 1.

\section{Defining the heat stress year}

Interannual variation in heat stress requires definition of the heat stress year (HSY). Logically, Northern and Southern Hemispheres will have different timings for the onset and peak heat stress and so are considered separately. For the period 1985-2017, the percentage of heat-stressed reef pixels (i.e. $\mathrm{HS} \geq 1{ }^{\circ} \mathrm{C}$ ) was determined for each day of the year (separately for each hemisphere). Daily percentages were then averaged for each month. The HSY was identified as beginning from the month in which the climatologically lowest percentage of stressed reefs occurred.

\section{Analysis of annual variation}

The HS product is applied to identify if (and when) heat stress is present for a reef pixel (i.e. HS $\geq 1{ }^{\circ} \mathrm{C}$ ), which may occur for a single day or an extended period. The DHW product combines the duration and intensity of heat stress (i.e. the magnitude of the HS) to give the accumulated heat stress from which predictions of bleaching severity are determined. Using the derived austral and boreal HSY, three annual datasets were created: the annual maximum HS, the annual maximum DHW and the annual number of days of heat stress (i.e. $\mathrm{HS} \geq 1{ }^{\circ} \mathrm{C}$ ). The percentage of reef pixels each year corresponding to the following levels of heat stress was determined:

(1) annual maximum $\mathrm{HS} \geq 1{ }^{\circ} \mathrm{C}$, indicating that heat stress was present at some point during the year, leading to $\mathrm{DHW}>0{ }^{\circ} \mathrm{C}$-weeks, and the triggering of the CRW Bleaching Warning level (Liu et al. 2014);

(2) the threshold of DHW $\geq 2{ }^{\circ} \mathrm{C}$-weeks, indicated by Hughes et al. (2017) as relating to low-level bleaching on the Great Barrier Reef during 2016; and 
Table 1 Numbers of reef-containing satellite pixels at the $5 \mathrm{~km}$ resolution of CoralTemp for the various regions considered in this analysis

\begin{tabular}{lllr}
\hline Number of reef pixels & Indian Ocean & Pacific Ocean & Atlantic Ocean \\
\hline Northern Hemisphere & 6716 & 12,775 & 6687 \\
Southern Hemisphere & 5329 & 23,087 & 306 \\
\hline
\end{tabular}

(3) accumulated heat stress levels of DHW $\geq 4$ and $\geq 8{ }^{\circ} \mathrm{C}$-weeks, which correspond to the $\mathrm{CRW}$ Bleaching Alert 1 and Alert 2 levels, respectively (Liu et al. 2014).

Previous versions of the CRW DHW product have been compared against bleaching survey data, from which it was concluded that DHW $\geq 4{ }^{\circ} \mathrm{C}$-weeks is a measure of ecologically significant bleaching, while DHW $\geq 8{ }^{\circ} \mathrm{C}$-weeks is considered to be characteristic of severe bleaching with ecologically significant mortality (Eakin et al. 2010; Liu et al. 2013; Heron et al. 2016a). CRW is currently validating the Version 3.1 DHW product against bleaching observations. Anecdotal evidence suggests that the above interpretation for DHW $\geq 4$ and $\geq 8{ }^{\circ} \mathrm{C}$-weeks may be slightly conservative for some reef locations. In fact, Hughes et al. (2018b) suggested that a DHW Version 3.1 of $4{ }^{\circ} \mathrm{C}$-weeks is the heat stress at which mortality begins; however, their results came from the northern Great Barrier Reef (GBR), Australia, in 2016-the first significant mass bleaching in that region. The reefs of the northern GBR may therefore have been more sensitive to heat stress and hence may have exhibited bleaching and mortality at lower values of DHW than might normally be expected of most reefs globally. Here, we chose to use three DHW thresholds: a conservative $2{ }^{\circ} \mathrm{C}$-week threshold (indicative of at least low-level bleaching), and the well-established interpretation of DHW thresholds of 4 and $8{ }^{\circ} \mathrm{C}$-weeks that can be considered as ecologically significant bleaching and severe bleaching with ecologically significant mortality, respectively.

The DHW metric combines the intensity and duration of accumulated heat stress. Here, we consider the relative contributions of these components through time. Analysis of heat stress intensity was examined by determining statistics (mean, maximum and 90th percentile values) of the observed values of $\mathrm{HS} \geq 1{ }^{\circ} \mathrm{C}$ for each year. Analysis of heat stress duration was examined by determining statistics (mean, maximum and 90th percentile values) of the number of days that each reef pixel had HS $\geq 1{ }^{\circ} \mathrm{C}$ for each year.

Analyses were undertaken globally, for Northern and Southern Hemisphere reefs, for the three tropical ocean basins (Indian, Pacific and Atlantic) and for the northern and southern regions of each tropical ocean basin.
Outcomes presented here reflect the most informative results from these analyses. Since all analyses were initially performed as either Northern or Southern Hemisphere, counts of reef-containing pixels (Table 1) were used to weight results from individual regions for the basin and global analyses.

\section{Results}

\section{Defining the heat stress year}

The average percentage of reefs with heat stress (HS $\geq 1{ }^{\circ} \mathrm{C}$ ) for each month revealed an expected result-that the minimum extent of coral stress occurred during the winter in each hemisphere (Fig. 1). Based on these results, we define the heat stress year (HSY) for the Northern Hemisphere as February 1-January 31 (Fig. 1a), with the period referred to by the year at the beginning of the period (i.e. the year of February). The HSY for the Southern Hemisphere is offset from this by 6 months (Fig. 1b), August 1-July 31, defined by the minimum percentage of heat stress exposure during the austral winter. Since most of the austral heat stresses (and thus almost all bleaching) occurs in the later year of the period, we refer to the austral HSY using the year in which the period ends. This means that for both Northern and Southern Hemisphere analyses, the year referred to contains the peak heat stress; for example, 1998 refers to (1) August 1, 1997-July 31, 1998 for the Southern Hemisphere (peak heat stress in February); and (2) February 1, 1998-January 31, 1999 for the Northern Hemisphere (peak heat stress in August).

\section{Analysis of annual variation}

The proportion of reef pixels experiencing heat stress (i.e. HS $\geq 1{ }^{\circ} \mathrm{C}$ ) was mostly consistent at just over $50 \%$ for the first 2 decades of the record, with a marked increase during the most recent 12 years (Fig. 2; Table 2). The increasing trend in the proportion of reef pixels reaching DHW thresholds of 2, 4 and $8{ }^{\circ} \mathrm{C}$-weeks throughout the record and especially in the last 12 years was even more evident (Fig. 2; Table 2). In contrast to that for the $\mathrm{HS} \geq 1{ }^{\circ} \mathrm{C}$ threshold, the extent of reef pixels exposed to the DHW thresholds showed three clear peaks in 1998, 2010 and 

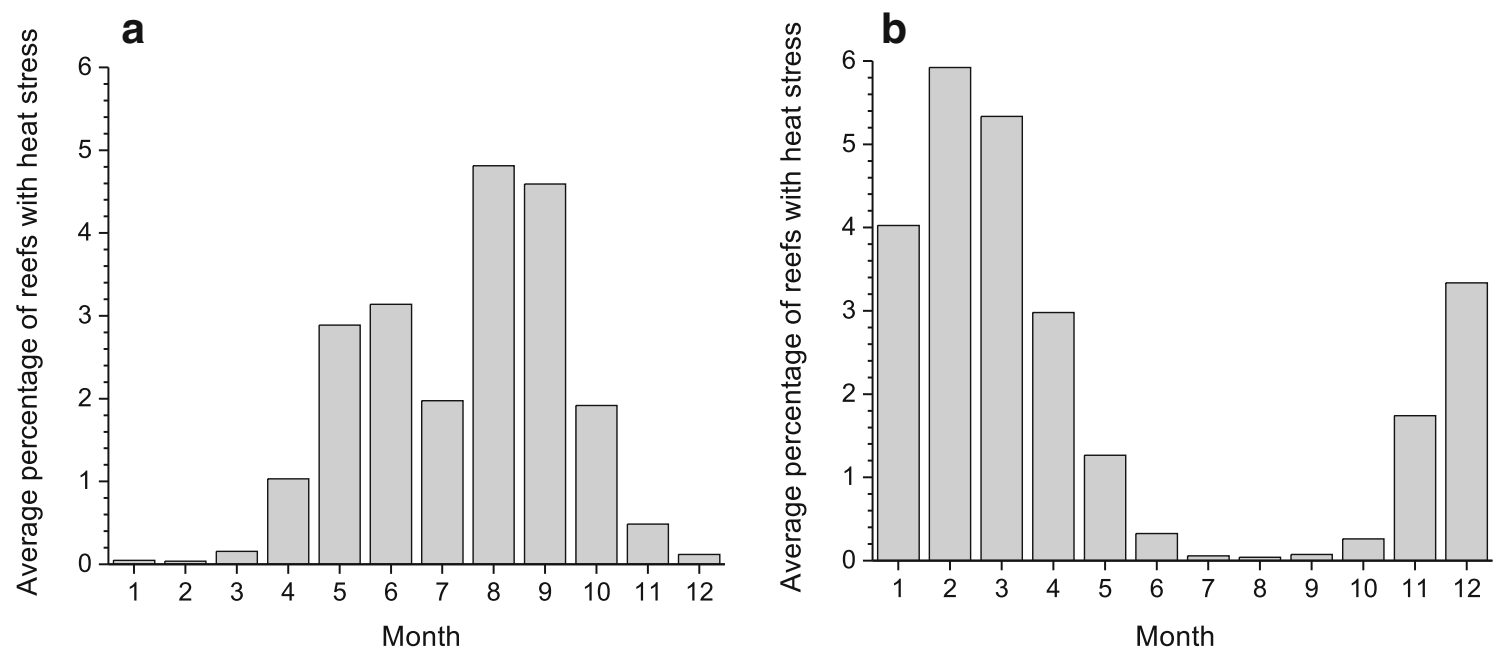

Fig. 1 Average, 1986-2017, percentage of reef pixels with heat stress for each month in the a Northern Hemisphere and b Southern Hemisphere

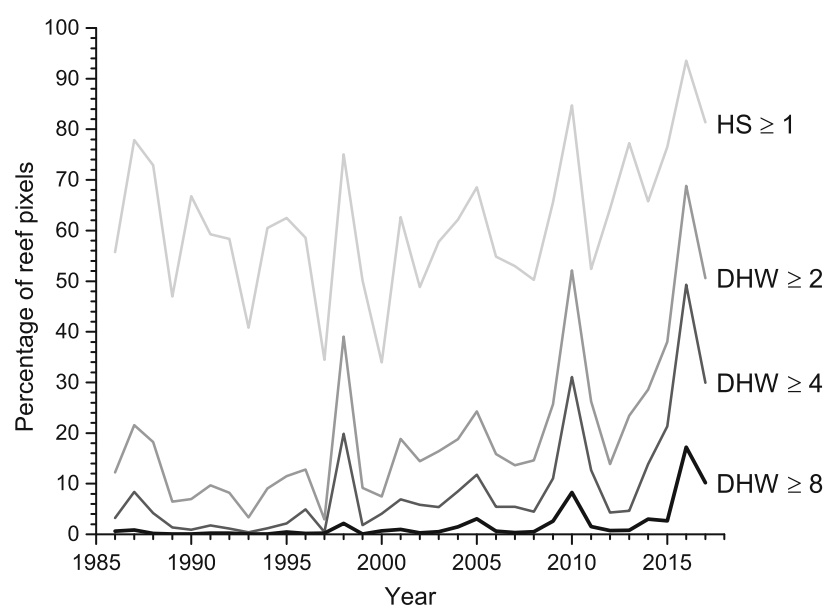

Fig. 2 Percentage of global reef pixels exposed to heat stress as determined using thresholds of HS and DHW
2016 corresponding to the three global bleaching events (Eakin et al. 2017).

Examination of the extent of exposure for the DHW $\geq 2{ }^{\circ} \mathrm{C}$-week threshold separately for the three tropical ocean basins (Fig. 3a) indicated 3 years-1998, 2010 and 2016 - for which a substantial proportion of reefs experienced levels of heat stress, likely to result in at least a low level of bleaching in all of the tropical ocean basins (i.e. global events). Analyses of extent of DHW $\geq 4{ }^{\circ} \mathrm{C}$-weeks indicate that periods of pan-tropical heat stress associated with ecologically significant bleaching occurred in 1998, 2010, 2015, 2016 and 2017 (Fig. 3b). For DHW $\geq 8{ }^{\circ} \mathrm{C}$ weeks, significant coral loss was predicted to have occurred in all three tropical ocean basins in 1998, 2010, 2016 and 2017 (Fig. 3c). Notably, there are other years in the record (e.g. 1988, 2005) in which one or two-but not all three-
Table 2 Rate of change in percentage of global reef pixels exposed to various levels of heat stress over three time periods, 1986-2017, 1986-2005 and 2006-2017

\begin{tabular}{lccc}
\hline Heat stress exposure & Trend (\%/year) & SE in trend (\%/year) & $p$ value \\
\hline $1986-2017$ (32 years) & & & \\
$\mathrm{HS} \geq 1{ }^{\circ} \mathrm{C}$ & 0.533 & 0.251 & 0.043 \\
$\mathrm{DHW} \geq 2{ }^{\circ} \mathrm{C}$ & 1.039 & 0.226 & 0.000 \\
$\mathrm{DHW} \geq 4{ }^{\circ} \mathrm{C}$ & 0.711 & 0.166 & 0.000 \\
$\mathrm{DHW} \geq 8{ }^{\circ} \mathrm{C}$ & 0.212 & 0.058 & 0.001 \\
$1986-2005(20$ years $)$ & & & \\
$\mathrm{HS} \geq 1{ }^{\circ} \mathrm{C}$ & 0.351 & 0.482 & 0.475 \\
$\mathrm{DHW} \geq 2{ }^{\circ} \mathrm{C}$ & 0.403 & 0.322 & 0.227 \\
$\mathrm{DHW} \geq 4{ }^{\circ} \mathrm{C}$ & 0.323 & 0.173 & 0.077 \\
$\mathrm{DHW} \geq 8{ }^{\circ} \mathrm{C}$ & 0.066 & 0.027 & 0.027 \\
$2006-2017(12$ years $)$ & & & 0.007 \\
$\mathrm{HS} \geq 1{ }^{\circ} \mathrm{C}$ & 2.906 & 0.853 & 0.016 \\
DHW $\geq 2{ }^{\circ} \mathrm{C}$ & 3.352 & 1.156 & 0.029 \\
DHW $\geq 4{ }^{\circ} \mathrm{C}$ & 2.477 & 0.969 & 0.037 \\
DHW $\geq 8{ }^{\circ} \mathrm{C}$ & 0.876 & 0.364 & \\
\hline
\end{tabular}




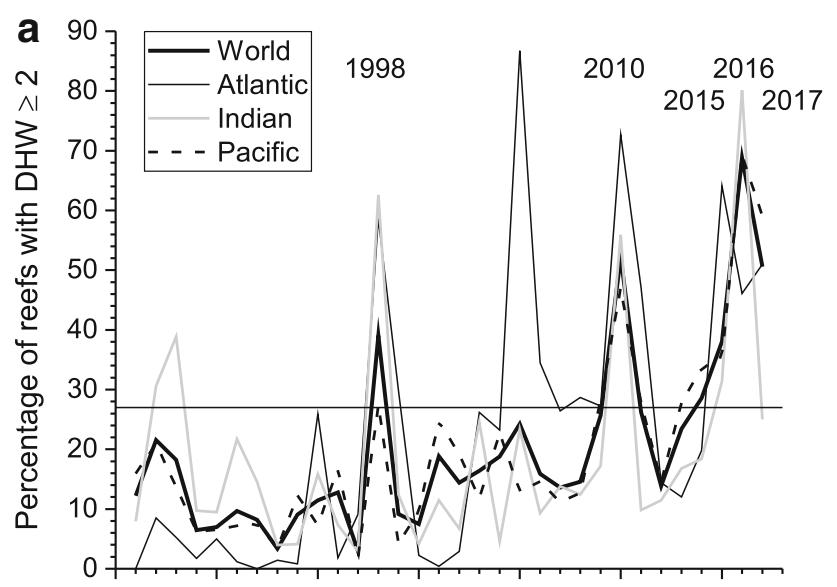

ocean basins showed extensive exposure to heat stress, resulting in significant regional (but not global) events.

The contribution of heat stress intensity through time varied across the six reef regions (Fig. 4). Significant trends $(p<0.05)$ in the maximum HS were observed only in the northern Atlantic (increasing) and southern Atlantic (decreasing). Northern Hemisphere maximum values increased, while those in the Southern Hemisphere decreased through the record. While $p$ values have been provided for each analysis, we note that the values analysed (HS $\geq 1{ }^{\circ} \mathrm{C}$ ) violate the assumption of normal distribution. Examination of spatial mean and 90th percentiles of annual maximum HS (not shown) revealed similar but smaller magnitude trends across the period 1985-2017.

The maximum duration of heat stress increased through

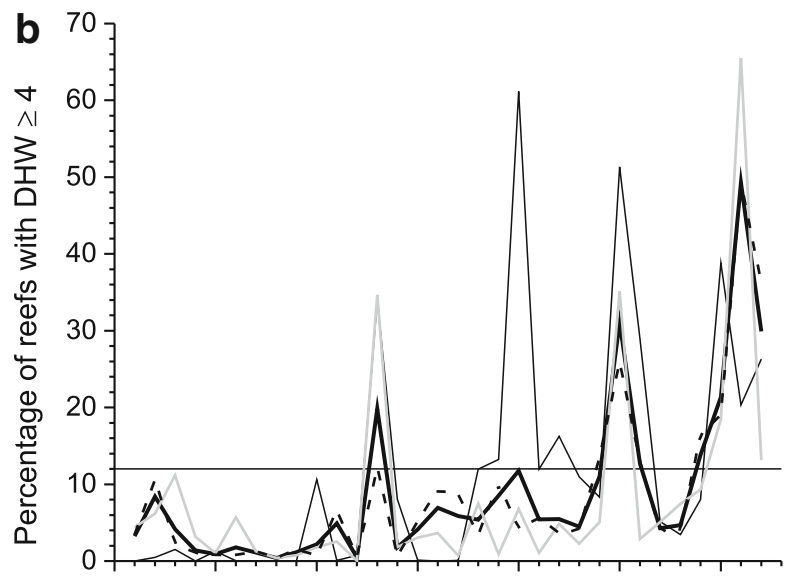
time in all six reef regions (Fig. 5). The only non-significant $(p>0.05)$ increases were for the southern Indian and northern Pacific regions, which were the only two regions that experienced event durations in excess of 160 days (approximately 5 months). Those unusually long durations affected the significance of the trends. We again note that while $p$ values have been provided, these can only be considered indicative of statistical significance, as the values analysed were not normally distributed. Spatial mean and 90th percentiles of annual maximum duration of heat stress (not shown) revealed similar but smaller trends across the period 1985-2017.

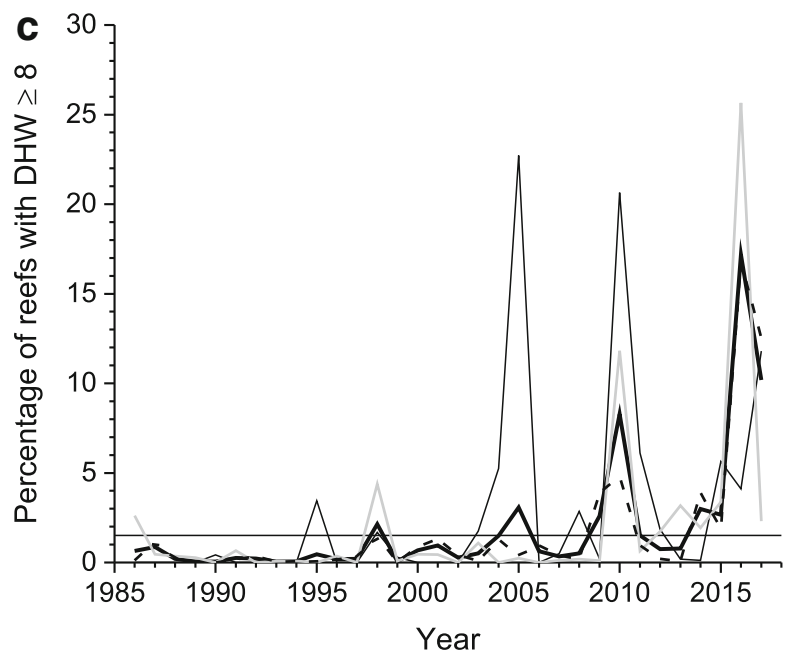

\section{Discussion}

Heat stress years (HSYs) were defined as beginning February 1 and August 1 for the Northern and Southern Hemispheres, respectively. Heat stress at global reef locations, assessed using the HSYs, revealed a clear increase in the extent of accumulated heat stress events defined by DHW thresholds of 2,4 and $8{ }^{\circ} \mathrm{C}$-weeks. While annual maximum temperature increased in only two of six coral reef regions, the duration of accumulated heat stress increased in all six reef regions.

\section{Coral heat stress over the past 3 decades}

Fig. 3 Percentage of reef pixels globally and in the three tropical ocean basins exposed to bleaching-level heat stress as determined using thresholds a DHW $\geq 2$, b DHW $\geq 4$ and c DHW $\geq 8{ }^{\circ} \mathrm{C}$ weeks. The horizontal line in each panel indicates the threshold for the percentage of reef pixels required in each tropical ocean basin for a global heat stress event (explained in: discussion-defining a global bleaching event). Note that the vertical scale changes between the panels

The historical extent of exposure between 1985 and 2017 to any level of heat stress (HS $\geq 1{ }^{\circ} \mathrm{C}$ ) fluctuated through the record, but overall showed only a small positive trend with a much larger increase in the last 12 years. The increase in the latter part of the record may reflect the onset of a spatial broadening of heat stress extent driven by global warming, in which individual locations are exposed to locally extreme summertime temperature more frequently than in previous decades; however, noting the decrease during the first 2 decades, it may also represent an 


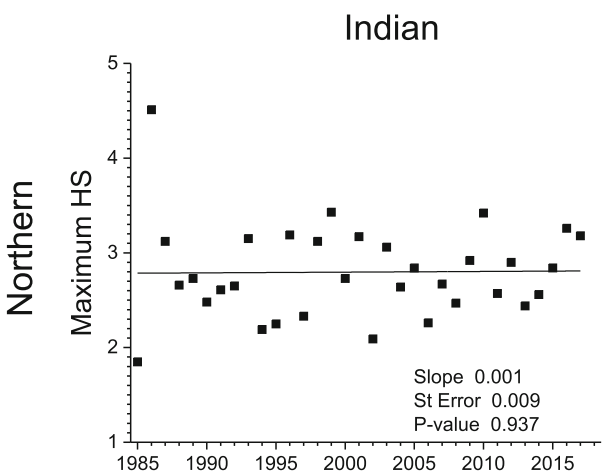

Pacific
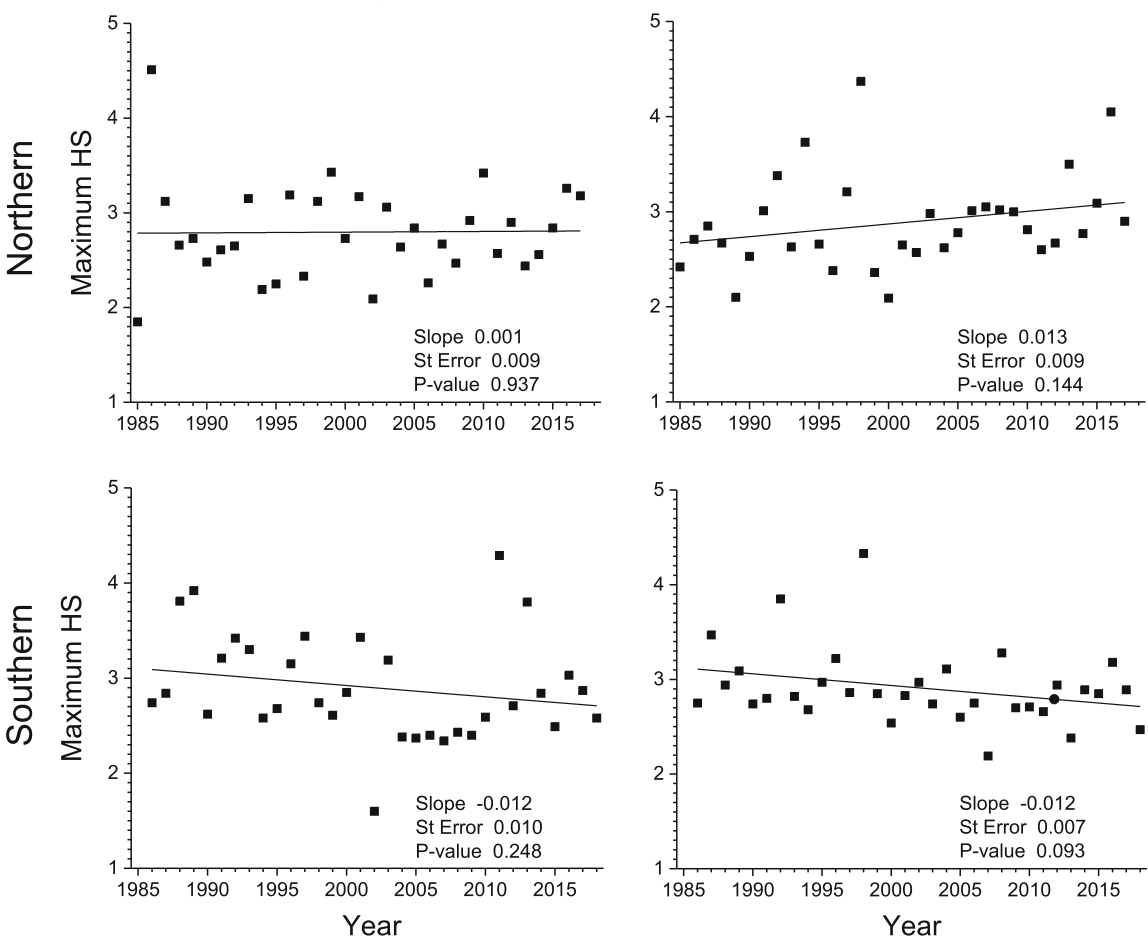
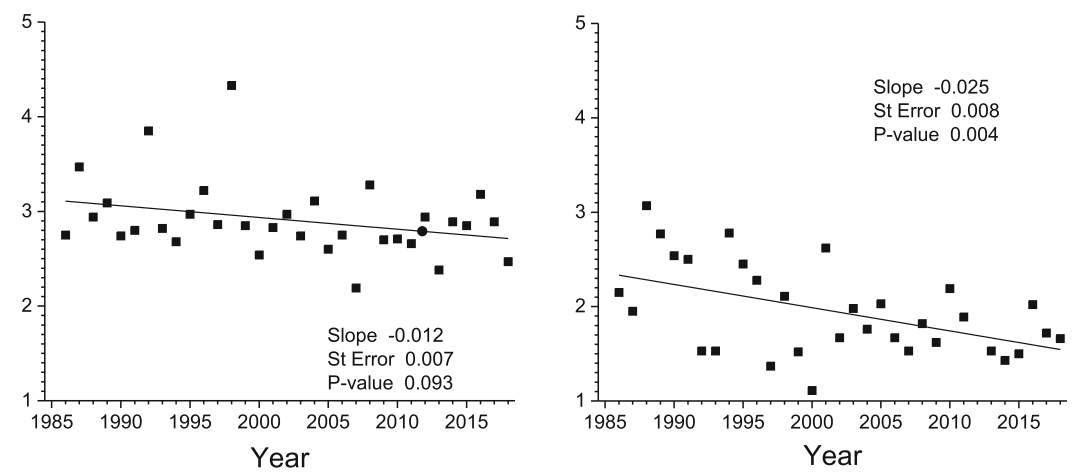

Error 0.008

Fig. 4 Annual variation in maximum HS observed for the Northern and Southern Hemisphere regions of the three tropical ocean basins

Indian
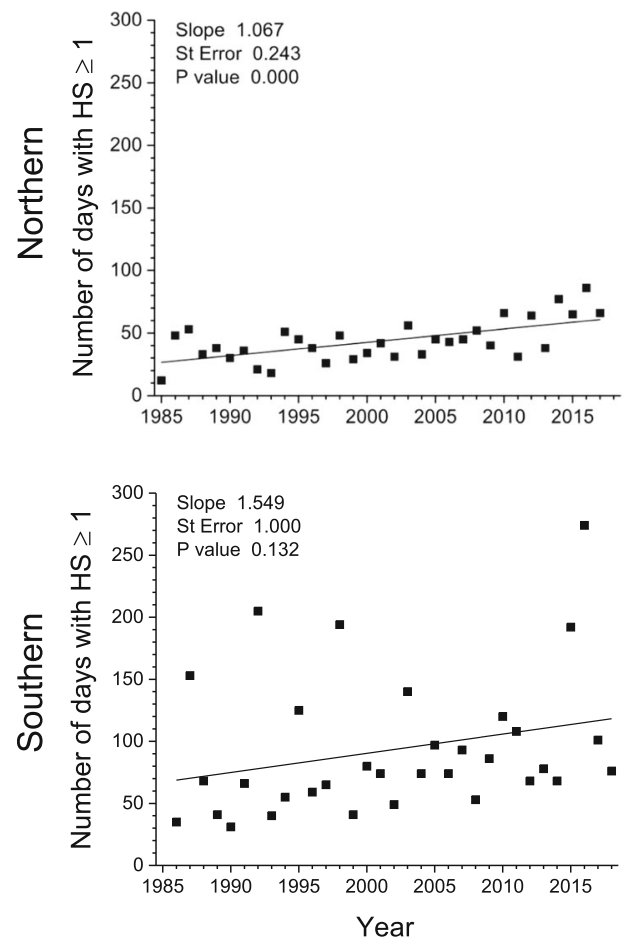

Pacific
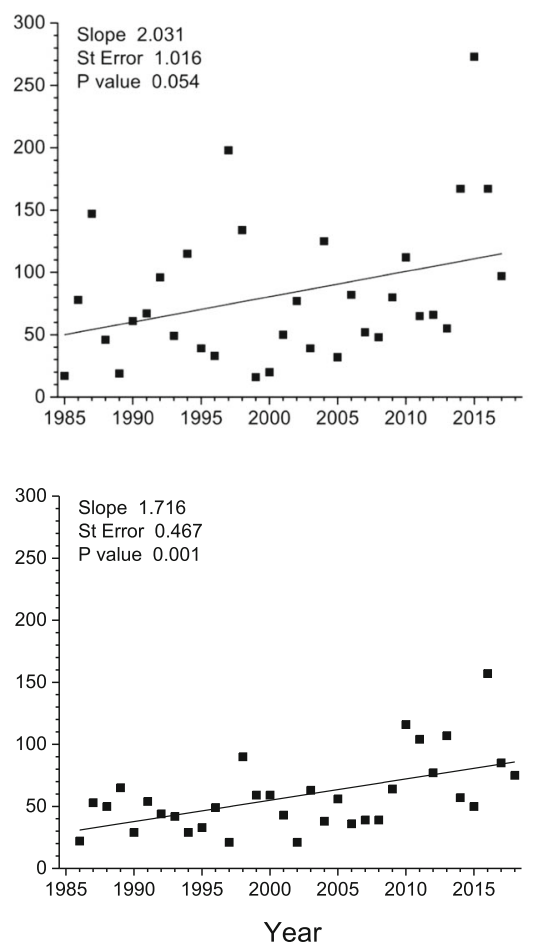

Atlantic

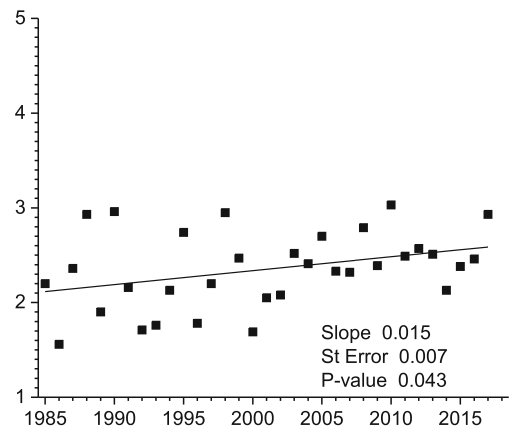


upward inflection of a longer cyclical variation that has a period comparable with or greater than the analysed record. Lough et al. (2018) described similar global heat stress patterns and trends over a period of 1871-2017, which tends to indicate that the trend is a climate change signal rather than a cyclical variation.

The proportion of reef locations exposed to heat stress is larger $(>50 \%)$ than might previously have been expected. This result is realistic, given that the annual maximum HS values represent a positive deviation from the expected summertime maximum temperature, for which a single daily value of $1{ }^{\circ} \mathrm{C}$ would not be uncommon, even historically.

The clear increase in the extent of accumulated heat stress (at all DHW thresholds) through the entire record is consistent with previous temperature-based analyses (e.g. Hoegh-Guldberg et al. 2014; Heron et al. 2016b; Eakin et al. 2018) and with observations of coral bleaching (Donner et al. 2017; Oliver et al. 2018). The consistency through time of the CoralTemp dataset has enabled direct comparison of past events.

The rapid increase in the extent of peak events though time is alarming. For example, Fig. $3 b$ clearly shows the rapid increase in the extent of DHW $\geq 4{ }^{\circ} \mathrm{C}$-weeks globally (which is also mirrored in Fig. 3a, b, i.e. DHW $\geq 2{ }^{\circ} \mathrm{C}$-weeks and $\mathrm{DHW} \geq 8{ }^{\circ} \mathrm{C}$-weeks, respectively). This is the reason for the rapid increase in the number of reefs that have seen bleaching worldwide as reported by Hughes et al. (2018a). The most eye-catching peaks in this graph are for 1987, 1998, 2010 and 2016 when the percentage of reefs with $\mathrm{DHW} \geq 4{ }^{\circ} \mathrm{C}$-weeks was $8.4 \%$, $19.8 \%, 31.1 \%$ and $49.3 \%$, respectively (it must be noted that 2015 and 2017 were $21.4 \%$ and $29.9 \%$, respectively). Although four peak events are too few to perform a valid trend analysis, it is extremely tempting to look at this graph and expect another peak event sometime in the mid-2020s, where significant bleaching (i.e. DHW $\geq 4{ }^{\circ} \mathrm{C}$-weeks) is experienced on more than $60 \%$ of the world's reefs, and if the multi-year event over 2015-2017 is an indicative of future events, the next peak may also be a multi-year event. This sharp increase in extent of bleaching-level thermal stress is mirrored in all basins with the exception of the Atlantic, where 2005 was a standout year with $61 \%$ of reefs reaching DHW $\geq 4{ }^{\circ} \mathrm{C}$-weeks. Nevertheless, the Atlantic continued to experience widespread bleaching-level thermal stress during 2010 and 2015, and although these years were slightly less than the extent during 2005, the values of $51 \%$ and $39 \%$ remain alarmingly high.

While severe heat stress events (DHW $\geq 8{ }^{\circ} \mathrm{C}$-weeks) have been observed at some reef pixels in all years (Fig. 3c), the increase through the study period has been dramatic. Prior to the 1998 event, the average global percentage of reef pixels exposed at this level was $0.3 \%$
(1986-1997). From 1998 to 2009, this exposure increased to $1.1 \%$ of reef pixels, on average. Since $2010,5.5 \%$ of reef pixels have, on average, reached or exceeded $8{ }^{\circ} \mathrm{C}$-weeks. Prior to 1998, there was no instance of the global proportion of severe heat stress exceeding $1 \%$ in the study period; of the 20 years since, ten have had severe heat stress at over $1 \%$ of reef pixels. The high percentage of reef pixels exposed to severe heat stress in 2005 was strongly driven by the regional event in the Caribbean (Atlantic basin), during which many reefs were severely damaged.

The 1998 value for the global percentage of reef pixels with $\mathrm{DHW} \geq 8{ }^{\circ} \mathrm{C}$-weeks of $2.1 \%$ was surpassed in seven subsequent bleaching years (Eakin et al. 2010, 2017; Heron et al. 2016b): 2005 (3.1\%), 2009 (2.6\%), $2010(8.3 \%)$, $2014(3.0 \%), 2015(2.7 \%), 2016(17.2 \%)$ and 2017 (10.2\%). That the four consecutive years 2014-2017 each had an extent of severely bleached reefs greater than in 1998 is an alarming fact that underlines the overall trend in the heat stress trend analyses presented here. The combined extent of severe heat stress from 2015 to 2017 was a more than 15-fold increase from the percentage of reefs with severe heat stress in 1998, affecting nearly one-quarter of reef locations $(23.5 \%)$.

The CoralTemp dataset will soon be extended back to 1981, with plans to integrate data from phase 2 of the European Space Agency's Climate Change Initiative SST programme (Merchant et al. 2014). This will allow the inclusion of heat stress from the 1982/83 ENSO event, which was at least the first widespread bleaching event (Coffroth et al. 1990) and may have been the first global bleaching event. Information from these earlier years will likely further contrast with the recent, rapid increase in heat stress and associated bleaching that has resulted from global warming.

\section{Defining a heat stress year}

The outcome of the analysis to define the heat stress year (HSY) periods supports the methodology of separating Northern from Southern Hemispheres, even for reef locations near the equator. The starting dates for each HSY (February 1 in the Northern Hemisphere; and August 1 in the Southern Hemisphere) were defined as the month with the minimum climatological average percentage of reef pixels with heat stress. These dates are sufficiently separated from the equinox timings (late March heading into the boreal summer; and late September heading into the austral summer), when the sun is directly over the equator (local solar maximum) that any heat stress near the equator would fall completely within the relevant HSY. Additionally, peak ocean temperature typically lags the local solar maximum by 1-2 months, which further separates nearequatorial heat stress from the starting date of the relevant 
HSY. The climatological minimum percentage of heat stress extent for both hemispheres was well below $0.1 \%$ (Fig. 1); such a low proportion indicates that any historical occurrence of heat stress during the minimum month is exceptional.

Temperature variability and resultant heat stress events in the equatorial region are exceptional, not conforming to the seasonality of non-equatorial regions (e.g. Barkley et al. 2018). Instead, equatorial oceans (especially the Pacific) are dominated by interannual, rather than intra-annual, variability (Donner 2011; Langlais et al. 2017). As such, equatorial heat stress events can occur independent of seasonal patterns-as transpired in the Central Pacific where El Niño-driven heat stress was present from April 2015 to May 2016 (Eakin et al. 2017).

While the analysis here indicates that long equatorial events, spanning HSYs, are exceptional in the historical record, this may not hold as climate change progresses. It may become necessary to consider the equatorial region (in which there may not be annual periodicity) separately from the Northern and Southern Hemispheres (in which the existing seasonal cycles persist). However, for the analysis presented here, heat stress in equatorial regions is, at least for the great majority, encapsulated within the defined HSY.

\section{Defining a global bleaching event}

The term "global bleaching event" has been used by many authors (e.g. Wilkinson 1998; Eakin et al. 2017; Oliver et al. 2018), and yet, there has been no quantitative definition of the term. The analyses presented here provide an opportunity to propose an objective definition for "global bleaching event". The event of 1998 is widely recognised as being the first global coral bleaching event (Wilkinson 1998; Oliver et al. 2018), as such the heat stress from this event provides a useful yardstick to objectively characterise bleaching events as being global. Qualitatively, events have been defined as global if bleaching is widespread in all three tropical ocean basins (Eakin et al. 2017). We therefore propose that if a threshold is used, it must be applied to each ocean basin separately. To include 1998 as a global bleaching event, each basin would have to exceed one of the three possible thresholds: (1) the percentage of reef pixels with $\mathrm{DHW} \geq 2{ }^{\circ} \mathrm{C}$-weeks exceeds $27 \%$ (indicative of widespread exposure to at least low-level bleaching), or (2) the percentage of reef pixels with $\mathrm{DHW} \geq 4{ }^{\circ} \mathrm{C}$-weeks exceeds $12 \%$ (indicative of exposure to greater heat stress linked to ecologically significant bleaching), or (3) the percentage of reef pixels with $\mathrm{DHW} \geq 8{ }^{\circ} \mathrm{C}$-weeks exceeds $1.5 \%$ (indicative of exposure to high heat stress linked to severe bleaching and ecologically significant mortality). These thresholds for extent (shown as horizontal lines in Fig. 3a-c) represent the minimum basin extents during 1998 (Tables 3, 4, 5). Applying this to the historical record (1986-2017) indicates that 1998, 2010, 2015 and 2016 meet all three criteria, while 2017 meets the second and third criteria (falling short of the first criterion by a narrow margin).

All three thresholds are therefore candidates for use as an objective definition of the term "global bleaching event". It seems logical that DHW $\geq 4{ }^{\circ} \mathrm{C}$-weeks can be used to define a "global bleaching event", since this is the lowest DHW value that is associated with ecologically significant bleaching levels.

In terms of event onset, it is possible to use the hemisphere results to see if the global bleaching event, when defined quantitatively, began in the northern HSY or the southern HSY. The 1998 event began during the 1998 southern HSY and continued into the 1998 Northern Hemisphere HSY. The 2010 event began in the 2010 southern hemisphere HSY, continuing through the 2010 northern HSY and into the subsequent 2011 southern HSY, therefore spanning almost 18 months. The third global event extended from the 2015 southern HSY through to the 2017 southern HSY (spanning August 1, 2014-July 31, 2017), hence remaining over the extent threshold of $12 \%$ in all tropical ocean basins for a total of 30 months. We note that bleaching was observed from June 2014 (Eakin et al. 2017) and may be the beginning of the global event; however, the quantitative threshold for widespread exposure in all three tropical ocean basins was first exceeded during the 2015 southern HSY.

Using the 1998 event to define a global event can be extended to evaluate the relative extent of heat stress conditions in subsequent global events-a Global Bleaching Index (GBI). We propose defining the GBI using the extent from the global DHW $\geq 4{ }^{\circ} \mathrm{C}$-weeks as this reflects ecologically significant global bleaching. By definition, the 1998 event has a GBI value of 1 (corresponding to a global extent of $19.8 \%$ ). From this, we see that 2015 was comparable with 1998; the years 2010 and 2017 were comparable and more extensive than in 1998; and the extent of heat stress in 2016 far exceeded those (Table 6). The GBI

Table 3 Percentage of reef pixels exposed to DHW $\geq 2{ }^{\circ} \mathrm{C}$-weeks (indicative of at least low-level bleaching) in the years designated as being global events. Note that the period labelled as "2015-2017" spans August 1, 2014-July 31, 2017

\begin{tabular}{lllllll}
\hline$\%$ & 1998 & 2010 & 2015 & 2016 & 2017 & $2015-2017$ \\
\hline Global & 39.1 & 52.1 & 38.0 & 68.8 & 50.6 & 85.5 \\
Indian & 62.6 & 55.9 & 31.4 & 80.1 & 25.0 & 90.8 \\
Pacific & 27.5 & 47.0 & 35.4 & 69.3 & 59.1 & 85.9 \\
Atlantic & 58.6 & 72.7 & 64.1 & 46.1 & 51.0 & 73.7 \\
\hline
\end{tabular}


Table 4 Percentage of reef pixels exposed to DHW $\geq 4{ }^{\circ} \mathrm{C}$-weeks (indicative of ecologically significant bleaching) in the years designated as being global events. Note that the period labelled as "2015-2017" spans August 1, 2014-July 31, 2017

\begin{tabular}{lllllll}
\hline$\%$ & 1998 & 2010 & 2015 & 2016 & 2017 & $2015-2017$ \\
\hline Global & 19.8 & 31.1 & 21.4 & 49.3 & 29.9 & 65.0 \\
Indian & 34.7 & 35.2 & 18.5 & 65.5 & 13.2 & 74.8 \\
Pacific & 12.2 & 26.0 & 19.1 & 49.3 & 36.2 & 64.9 \\
Atlantic & 34.1 & 51.3 & 38.8 & 20.3 & 26.3 & 48.1 \\
\hline
\end{tabular}

Table 5 Percentage of reef pixels exposed to DHW $\geq 8{ }^{\circ} \mathrm{C}$-weeks (indicative of severe bleaching and ecologically significant mortality) in the years designated as being global events. Note that the period labelled as "2015-2017" spans August 1, 2014-July 31, 2017

\begin{tabular}{llrlrrl}
\hline$\%$ & 1998 & 2010 & 2015 & 2016 & 2017 & $2015-2017$ \\
\hline Global & 2.1 & 8.3 & 2.7 & 17.2 & 10.2 & 23.5 \\
Indian & 4.4 & 11.8 & 3.4 & 25.7 & 2.3 & 28.4 \\
Pacific & 1.5 & 4.8 & 1.9 & 16.8 & 12.5 & 24.6 \\
Atlantic & 1.7 & 20.6 & 5.6 & 4.1 & 11.8 & 9.3 \\
\hline
\end{tabular}

Table 6 Global Bleaching Index (GBI) in the years with the greatest extent of heat stress, referenced to the percentage of reef pixels exposed to DHW $\geq 4{ }^{\circ} \mathrm{C}$-weeks in 1998. Note that the period labelled as "2015-2017" spans August 1, 2014-July 31, 2017

\begin{tabular}{lllllll}
\hline$\%$ & 1998 & 2010 & 2015 & 2016 & 2017 & $2015-2017$ \\
\hline GBI & 1 & 1.6 & 1.1 & 2.5 & 1.5 & 3.3 \\
\hline
\end{tabular}

allows a simple comparison of any global bleaching event with the 1998 event; for example, the number of reef pixels predicted to have significant bleaching in 2016 was 2.5 times greater than in 1998, while the combined impact in 2015-2017 was that 3.3 times as many reefs bleached in that period as bleached in 1998. Note that we only intend for the GBI to apply to those years that meet the definition of a global bleaching event (i.e. the Indian, Pacific and Atlantic basins each achieving a proportion of $12 \%$ of reefs with DHW $\geq 4{ }^{\circ} \mathrm{C}$-weeks).

\section{Temperature or time?}

The observed increase in accumulated heat stress (DHW) has been driven by increased duration rather than increased heat stress intensity. The finding that maximum HS has increased marginally, if at all, is underpinned by the existence of a theoretical limit to the maximum SST value
(Kleypas et al. 2008 and references therein). This is driven by the balance of incoming solar radiation and other radiation fluxes at the ocean surface. Unless the solar constant radically changes, or unless significant changes occur in atmospheric chemistry (in particular, the amount of water vapour), the maximum temperatures are unlikely to substantially change. In contrast, the maximum number of heat stress days per year has shown a significant upward trend.

This increase in duration of heat stress events-a lengthening of "summer" conditions-could lead to a shifted onset of bleaching events, an outcome that coral reef stakeholders may already be seeing. Furthermore, while summer maxima may be "capped" by the physics at the ocean-atmosphere interface, increases in summer and annual temperatures have been observed, which have led to a shortening of "winter" periods on reefs (Heron et al. 2016b) consistent with the fingerprint of global warming on seasons seen in the atmosphere (Santer et al. 2018). This may have significant implications in the phenology of coral processes (e.g. spawning, Keith et al. 2016).

Seasonal differences in warming are important when considering climate experiments on corals, which should not simply simulate climate change by incrementing temperature but rather determine the increased duration required to elevate annual average temperature conditions. For example, to simulate a $2{ }^{\circ} \mathrm{C}$ increase in annual average SST, it involves working out how long to hold the "summer" temperature at or near the maximum while increasing "winter" temperatures to arrive at the target average warming of $2{ }^{\circ} \mathrm{C}$.

Limiting warming to $2{ }^{\circ} \mathrm{C}$ above pre-industrial levels has been demonstrated as insufficient to save the great majority of coral reefs (Frieler et al. 2013) and other marine ecosystems (Gattuso et al. 2015). The observed increase in heat stress described here, and the concomitant escalation in coral bleaching, has occurred with a warming of $\sim 1{ }^{\circ} \mathrm{C}$ from pre-industrial times (Eakin et al. 2018). Further, warming is projected, which unless averted will continue the relentless march of mass coral bleaching and lead to further loss of coral reefs around the world.

Acknowledgements Coral Reef Watch and ReefSense staff were fully supported, and this study was partially supported by NOAA Grant NA14NES4320003 (Cooperative Institute for Climate and Satellites-CICS) at the University of Maryland/ESSIC. The scientific results and conclusions, as well as any views or opinions expressed herein, are those of the author(s) and do not necessarily reflect the views of NOAA or the Department of Commerce.

\section{Compliance with ethical standards}

Conflict of interest On behalf of all authors, the corresponding author states that there is no conflict of interest. 
Open Access This article is distributed under the terms of the Creative Commons Attribution 4.0 International License (http://crea tivecommons.org/licenses/by/4.0/), which permits unrestricted use, distribution, and reproduction in any medium, provided you give appropriate credit to the original author(s) and the source, provide a link to the Creative Commons license, and indicate if changes were made.

\section{References}

Barkley HC, Cohen AL, Mollica NR, Brainard RE, Rivera HE, DeCarlo TM, Lohmann GP, Drenkard EJ, Aplert AE, Young CW, Vargas-Angel B, Lino C, Oliver TA, Pietro KR, Luu VH (2018) Repeat bleaching of a central Pacific coral reef over the past six decades (1960-2016). Communications Biology 1:177. https://doi.org/10.1038/s42003-018-1083-7

Blunden J, Arndt DS (eds) (2018) State of the climate in 2017. Bulletin of the American Meteorological Society 99:Si-S332

Bond NA, Cronin MF, Freeland H, Mantua N (2015) Causes and impacts of the 2014 warm anomaly in the NE Pacific. Geophys Res Lett 42:3414-3420

Coffroth MA, Lasker HR, Oliver JK (1990) Coral Mortality Outside of the Eastern Pacific During 1982-1983: Relationship to El Niño. Coral Reefs 52:141-182

Donner SD (2011) An evaluation of the effect of recent temperature variability on the prediction of coral bleaching events. Ecol Appl 21:1718-1730

Donner SD, Rickbeil GJM, Heron SF (2017) A new, high-resolution global mass coral bleaching database. PLoS ONE 12(4): 0175490

Eakin CM, Liu G, Gomez AM, De La Cour JL, Heron SF, Skirving WJ, Geiger EF, Marsh BL, Tirak KV, Strong AE (2017) Ding, dong, the witch is dead (?)-Three years of global coral bleaching 2014-2017. Reef Encounter 32:33-38

Eakin CM, Lough JM, Heron SF, Liu G (2018) Climate variability and change: monitoring data and evidence for increased coral bleaching stress. In: van Oppen MJH, Lough JM (eds) Coral bleaching. Patterns, processes, causes and consequences. Springer International Publishing, Cham, Switzerland, pp. 51-84

Eakin CM, Morgan JA, Heron SF, Smith TB, Liu G, Alvarez-Filip L, Baca B, Bartels E, Bastidas C, Bouchon C, Brandt M (2010) Caribbean corals in crisis: Record thermal stress, bleaching, and mortality in 2005. PLoS ONE 5:e13969

Frieler K, Meinshausen M, Golly A, Mengel M, Lebek K, Donner SD, Hoegh-Guldberg $\mathrm{O}$ (2013) Limiting global warming to $2{ }^{\circ} \mathrm{C}$ is unlikely to save most coral reefs. Nat Clim Chang 3:165-170

Gattuso J-P, Magnan A, Billé R, Cheung WWL, Howes EL, Joos F, Allemand D, Bopp L, Cooley SR, Eakin CM, Hoegh-Guldberg O, Kelly RP, Pörtner H-O, Rogers AD, Baxter JM, Laffoley D, Osborn D, Rankovic A, Rochette J, Sumaila UR, Treyer S, Turley C (2015) Contrasting futures for ocean and society from different anthropogenic $\mathrm{CO}_{2}$ emissions scenarios. Science 349:aac4722

Glynn PW, D'Croz L (1990) Experimental evidence for high temperature stress as the cause of El Niño-coincident coral mortality. Coral Reefs 8:181-192

Heron SF, Johnston L, Liu G, Geiger EF, Maynard JA, De La Cour JL, Johnson S, Okano R, Benavente D, Burgess TFR, Iguel J, Perez D, Skirving WJ, Strong AE, Tirak K, Eakin CM (2016a) Validation of reef-scale thermal stress satellite products for coral bleaching monitoring. Remote Sens 8:59

Heron SF, Maynard J, van Hooidonk R, Eakin CM (2016b) Warming trends and bleaching stress of the world's coral reefs 1985-2012. Sci Rep 6:38402
Hoegh-Guldberg O (1999) Climate change, coral bleaching and the future of the world's coral reefs. Mar Freshw Res 50:839-866

Hoegh-Guldberg O, Cai R, Poloczanska ES, Brewer PG, Sundby S, Hilmi K, Fabry VJ, Jung S (2014) The Ocean. In: Barros VR, Field CB, Dokken DJ, Mastrandrea MD, Mach KJ, Bilir TE, Chatterjee M, Ebi KL, Estrada YO, Genova RC, Girma B, Kissel ES, Levy AN, MacCracken S, Mastrandrea PR, White LL (eds) Climate change 2014: Impacts, adaptation, and vulnerability. Part B: regional aspects. Contribution of Working Group II to the Fifth Assessment Report of the Intergovernmental Panel on Climate Change. Cambridge University Press, Cambridge, United Kingdom and New York, NY, USA, pp. 1655-1731

Hughes TP, Anderson KD, Connolly SR, Heron SF, Kerry JT, Lough JM, Baird AH, Baum JK, Berumen ML, Bridge TC, Claar DC, Eakin CM, Gilmour JP, Graham NAJ, Harrison H, Hobbs JA, Hoey AS, Hoogenboom M, Lowe RJ, McCullock MT, Pandolfi JM, Pratchett M, Schoepf V, Torda G, Wilson SK (2018a) Spatial and temporal patterns of mass bleaching of corals in the Anthropocene. Science 359:80-83

Hughes TP, Kerry JT, Álvarez-Noriega M, Álvarez-Romero JG, Anderson KD, Baird AH, Babcock RC, Beger M, Bellwood DR, Berkelmans R, Bridge TC, Butler I, Byrne M, Cantin NE, Comeau S, Connolly SR, Cumming GS, Dalton SJ, Diaz-Pulido G, Eakin CM, Figueira WF, Gilmour JP, Harrison HB, Heron SF, Hoey AS, Hobbs J-PA, Hoogenboom MO, Kennedy EV, Kuo C, Lough JM, Lowe RJ, Liu G, McCulloch MT, Malcolm HA, McWilliam MJ, Pandolfi JM, Pears RJ, Pratchett MS, Schoepf V, Simpson T, Skirving WJ, Sommer B, Torda G, Wachenfeld DR, Willis BL, Wilson SK (2017) Global warming and recurrent mass bleaching of corals. Nature 543:373-377

Hughes TP, Kerry JT, Baird AH, Connolly SR, Dietzel A, Eakin CM, Heron SF, Hoey AS, Hoogenboom MO, Liu G, McWilliam MJ, Pears RJ, Pratchett MS, Skirving WJ, Stalla JS, Torda G (2018b) Global warming transforms coral reef assemblages. Nature 556:492-496

Jokiel PL, Coles SL (1990) Response of Hawaiian and other IndoPacific reef corals to elevated temperature. Coral Reefs 8:155-162

Keith SA, Maynard JA, Edwards AJ, Guest JR, Bauman AG, van Hooidonk R, Heron SF, Berumen ML, Bouwmeester J, Piromvaragorn S, Rahbek C, Baird AH (2016) Coral mass spawning predicted by rapid seasonal rise in ocean temperature. Proc $\mathrm{R}$ Soc Lond B Biol Sci 283:20160011

Kleypas JA, Danabasoglu G, Lough JM (2008) Potential role of the ocean thermostat in determining regional differences in coral reef bleaching events. Geophys Res Lett 35:L03613

Langlais C, Lenton A, Heron SF, Evenhuis C, Sen Gupta A, Brown JN, Kuchinke M (2017) Coral bleaching pathways under the control of regional temperature variability. Nat Clim Chang 7:839-844

Liu G, Heron SF, Eakin CM, Muller-Karger FE, Vega-Rodriguez M, Guild LS, De La Cour JL, Geiger EF, Skirving WJ, Burgess TFR, Strong AE, Harris A, Maturi E, Ignatov A, Sapper J, Li J, Lynds S (2014) Reef-scale thermal stress monitoring of coral ecosystems: New 5-km global products from NOAA Coral Reef Watch. Remote Sens 6:11579-11606

Liu G, Rauenzahn JL, Heron SF, Eakin CM, Skirving WJ, Christensen TRL, Strong AE (2013) NOAA Coral Reef Watch $50 \mathrm{~km}$ satellite sea surface temperature-based decision support system for coral bleaching management. NOAA Technical Report NESDIS 143, NOAA/NESDIS, College Park, MD. 33 pp

Liu G, Skirving WJ, Geiger EF, De La Cour JL, Marsh BL, Heron SF, Tirak KV, Strong AE, Eakin CM (2017) NOAA Coral Reef Watch's $5 \mathrm{~km}$ satellite coral bleaching heat stress monitoring product suite version 3 and four-month Outlook version 4. Reef Encounter 32:39-45 
Lough JM, Anderson KD, Hughes TP (2018) Increasing thermal stress for tropical coral reefs: 1871-2017. Scientific Reports 8:6079. https://doi.org/10.1038/s41598-018-24530-9

Maturi E, Harris A, Mittaz J, Sapper J, Wick G, Zhu X, Dash P, Koner $P$ (2017) A new high-resolution sea surface temperature blended analysis. Bulletin of the American Meteorological Society 98:1015-1026

Merchant CJ, Embury O, Roberts-Jones J, Fiedler E, Bulgin CE, Corlett GK, Good S, McLaren A, Rayner N, Morak-Bozzo S, Donlon C (2014) Sea surface temperature datasets for climate applications from Phase 1 of the European Space Agency Climate Change Initiative (SST CCI). Geoscience Data Journal 1:179-191

Oliver JK, Berkelmans R, Eakin CM (2018) Coral Bleaching in Space and Time. In: van Oppen MJH, Lough JM (eds) Coral Bleaching.
Patterns, processes, causes and consequences. Springer International Publishing, Cham, Switzerland, pp. 27-50

Roberts-Jones J, Fiedler EK, Martin MJ (2012) Daily, global, highresolution SST and sea ice reanalysis for 1985-2007 using the OSTIA system. Journal of Climate 25:6215-6232

Santer BD, Po-Chedley S, Zelinka MD, Cvijanovic I, Bonfils C, Durack PJ, Fu Q, Kiehl J, Mears C, Painter J, Pallotta G, Solomon S, Wentz FJ, Zhi Zou C-Z (2018) Human influence on the seasonal cycle of tropospheric temperature. Science 361:eaas8806

Wilkinson CR (ed) (1998) Status of coral reefs of the world: 1998. Australian Institute of Marine Science, Townsville

Publisher's Note Springer Nature remains neutral with regard to jurisdictional claims in published maps and institutional affiliations. 